\title{
DESIGN-BASIS JUSTIFICATION FOR IMPLEMENTING TARGETED ENERGY RELEASE IN TEST OBJECTS OF THE IMPULSE GRAPHITE REACTOR
}

\author{
Vityuk V.A. ${ }^{1}$, Vityuk G.A. ${ }^{1,2}$, Skakov M.K. ${ }^{1}$, Zhagiparova L.K. ${ }^{1}$ \\ ${ }^{1}$ National Nuclear Center of the Republic of Kazakhstan, Kurchatov, Kazakhstan \\ 2 D. Serikbayev East Kazakhstan technical university, Ust-Kamenogorsk, Kazakhstan, \\ galina-shmeleova@mail.ru
}

\begin{abstract}
The article presents the approaches and technical solutions applied to assure preset axial and radial distribution of energy release in simulative fuel rods and fuel assemblies in the tests at the impulse graphite reactor. It considers the procedure for the design-basis justification of solutions that provide a given volume distribution of energy release in a test unit. The considerations are based on the example of heterogeneous fuel assemblies with the altitude separation of enriched fuel into two zones by a depleted uranium layer used to reproduce fissile material. The implementation of the procedure and making appropriate technical solutions made it possible to provide a targeted profile of the axial and radial distribution of energy release in a simulative fuel assembly at the design stage of an irradiation device. By the result of study, it is demonstrated that uniform radial energy release and targeted average energy release in upper and lower fission zones of experimental fuel assembly could be obtained at the level of $90.6 \mathrm{~W} / \mathrm{g}\left(\mathrm{UO}_{2}\right)$ and $74 \mathrm{~W} / \mathrm{g}\left(\mathrm{UO}_{2}\right)$, respectively. The measures include profiling of fuel pellets enrichment in fuel rods, using the pellets with an absorber at the zone ends, and a certain altitudinal positioning of the irradiation device in the reactor.
\end{abstract}

Keywords: Impulse graphite reactor, fuel assembly, energy release, power profile, fissile zone

\section{Introduction}

The experimental Justification of workability of nuclear fuel is the significant aspect of the decision making of its using. The complex of activities in this direction (both calculations and experiments) is devoted to the modeling of the fuel behavior in the conditions, which could lead to the progression of emergency mode with the core melting as consequence. The nuclear fuel tests in the research reactors are the most appropriate direct method to receive such experimental information which may be used both for experimental evaluation of fuel roads and fuel assemblies workability and to support the verification process of computer models and codes for corresponding calculations. Only several research nuclear reactors in the world possess the characteristics, which make it possible to carry-out the tests with fuel rods and fuel assemblies destruction. Among them the impulse graphite reactor IGR (National Nuclear Center, Kazakhstan), TRIGA type reactors including ACRR (Sandia Lab., USA), NSRR (Japan atomic energy agency), CABRI (French Commissariat on nuclear energy and alternative energy sources), BR-2 (SCK-CEN, Belgium), TREAT (Idaho lab., USA) and now stopped SCARABEE (France) [1-7].

In fact at present only IGR is actively used for experimental investigations of accidental conditions with the core melting for fuel assemblies with the loading up to $8 \mathrm{~kg}$ of $\mathrm{UO}_{2}$. Many years the experimental programs are successfully implemented at the IGR. At the moment the researches are focused on study of fuel pins and fuel assemblies behavior in severe accident conditions at the fast sodium reactors designed in Japan and France [8-11]. Other reactor designers are interested in such experimental programs realization also [12, 13].

The research thermal neutrons impulse nuclear reactor IGR with a homogeneous uranium-graphite core is a unique source of neutron and gamma radiation with high dynamics of power change. In the IGR reactor, the neutron flux can reach a value of $7 \cdot 10^{16} \mathrm{~cm}^{-2} \cdot \mathrm{s}^{-1}$, which makes possible to run the dynamic tests of fuel rods and fuel assemblies in transient and emergency modes. Implementation of targeted energy release is an important task when testing the simulative fuel rods and fuel assemblies in the IGR reactor. The solution to this problem should assure both the power required by the test conditions and the specific power profile in each volume of the tested structure. 
The power level of the tested fuel rods and fuel assemblies during their irradiation in the IGR depends on the parameters of the neutron field in the experimental channel, spatial and material characteristics of the device with fuel rods under irradiation. The spectrum and shape of the neutron field of the reactor themselves strongly depend on a number of factors: core temperature, position of the control rods, configuration and material composition of the irradiation device. In this regard, prior to the active phase of the tests, a complex of auxiliary studies shall be performed; to include calculation and experimental studies aimed at determining the coupling coefficient between the energy parameters of the test object and the reactor, and the nature of its changes during the reactor experiment [14-16]. Based on the auxiliary studies, we determine and analyze a reactor power diagram, which provides specified profile of power change on the test object and integrated energy release in the fuel. Even before that, while designing the irradiation device with fuel rods, solutions should be made providing the targeted volumetric distribution of energy release in the test object.

The requirements to the energy distribution in the fuel rods and fuel assemblies are determined by the test goals. This may include, for example, the need to reconstruct the energy release profile of a fuel assembly in the conditions of its operation in an actual power reactor or providing local bursts of energy release in the specified volumes to simulate transient and emergency processes. In some cases, the customer requires to ensure most uniform profile of the volumetric energy release in a given volume of fuel, for example, to ensure simultaneous melting of a given volume. At the same time, the quality and validity of the technical solutions undertaken to ensure a given energy release largely determines the degree of achievement of the test goal and the value of their results.

The paper discusses the approaches and technical solutions applied during preparation of the tests at the IGR to ensure targeted axial and radial profile of energy release in simulative fuel rods and fuel assemblies, as well as examples of their implementation.

\section{The problem of FA energy release profiling during the test preparation at the IGR}

\subsection{The IGR core}

The structure of the IGR reactor is a masonry of graphite blocks assembled into columns, placed in a steel cylindrical body with a helium medium. The graphite blocks of the reactor core are impregnated with an aqueous solution of uranyl nitrate (uranyldinitrate) with uranium concentration of $3.1 \mathrm{~g}$ per $1 \mathrm{~kg}$ of graphite. The core consists of fixed and moving parts surrounded by side and butt graphite reflectors. The shape of the core is like cubic: its dimensions in the cross-section are $1.400 \times 1.400 \mathrm{~mm}$; the height of the movable part of the masonry $-1.463 \mathrm{~mm}$; the height of the fixed part of the masonry is $1.332 \mathrm{~mm}$. The reactor has a central and lateral experimental channels (CEC and LEC), which are equipped with loop watercooled devices. The reactor is operated and protected by 16 graphite control rods with a gadolinium oxide absorber [15].

\subsection{The axial energy release profile}

The axial distribution of the neutron flux in an empty CEC of the reactor is presented in Figure 1 . The maximum flux corresponds to the center of the reactor core (mark "66.5"). However, as for the center of the core, the flow is not symmetrical since different amounts of reflectors are placed above and below the core. The shape of the neutron flux distribution in the CEC is also affected by the position of the control rods.

Due to the rather small dimensions of the core, any object placed in the CEC significantly affects the configuration of the neutron field. In case of a sufficiently uniform design of the irradiation device with a fuel rod or fuel assembly filled with fuel pellets with the same ${ }^{235}$ Ucontent, the axial profile of energy release in the fuel cells will, in general, correspond to the profile of the neutron field in an empty CEC (Figure 2) [18]. Taking the above into account, when it is necessary to assure energy release distribution in fuel rods, obeying to the dependence $\mathrm{y}=\mathrm{k} \operatorname{Cos} \mathrm{x}$, control may be provided by determining the optimal altitude level of the FA relative to the center of the core.

In this case, power surges will be observed at the ends of the fuel rods due to the increased neutron flux compared to other regions (see Figure 2). The neutrons entering the simulative fuel assembly installed in the CEC from the IGR core are absorbed by the ${ }^{235} \mathrm{U}$ in the FA fuel. The higher the ${ }^{235} \mathrm{U}$ content in a given FA volume, the more neutrons from IGR would be absorbed in this volume. The pellets located close to the fuel rod ends absorb the neutrons coming both from the side and from the ends of the fuel rods. Accordingly, at the ends of fuel rods with relatively high ${ }^{235} \mathrm{U}$ contents, an increase in neutron flux causing nuclear reactions and an increase in energy release would be observed. 


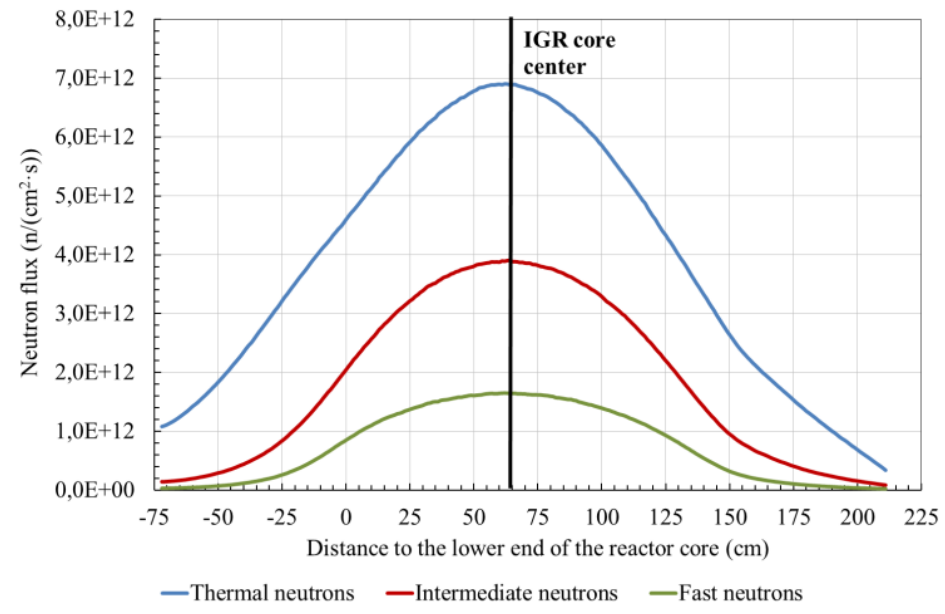

Fig.1. Neutron field parameters in an empty CEC (IGR power - 1MW)

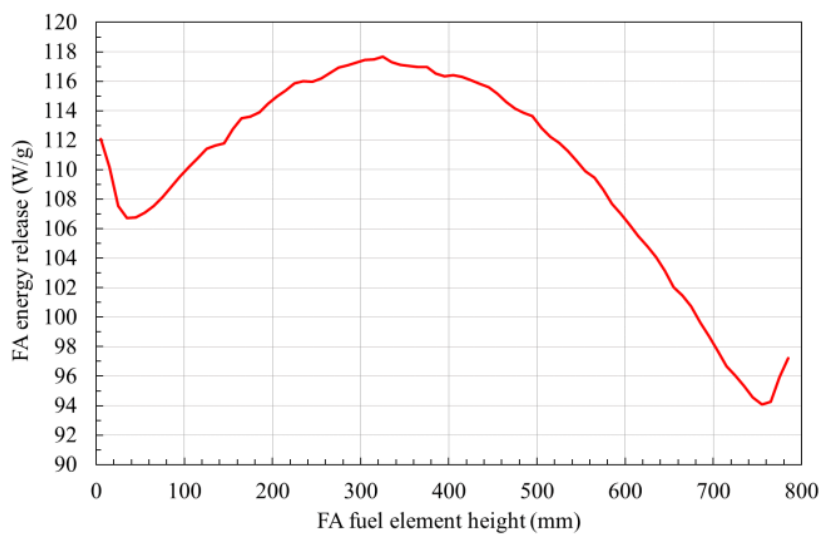

Fig.2. Axial energy release profile in a fuel rod of an irradiation device with a uniform height structure

A similar pattern would be at the junctions of the pellets enriched with ${ }^{235} \mathrm{U}$ and the pellets with depleted uranium. The pellets with ${ }^{235} \mathrm{U}$ content of $0.27 \%$, are often used in experiments for modeling fuel assemblies of fast neutrons containing blanket layers. Sometimes, the term "breeding blanket" is used to name such layers.

\subsection{The axial energy release profile}

The radial energy release profile in the fuel assemblies during the IGR tests is determined, first of all, by the assembly design. So, if a single-row symmetric arrangement of fuel rods with a uniform ${ }^{235} \mathrm{U}$ content in the pellets throughout the entire fuel assembly volume and a uniform symmetric design of the irradiator device is used, the energy release in the volumes of different fuel rods at the same altitude level would be practically the same. In asymmetric fuel rod arrangement with fuel rods sufficiently close to each other in a single-row fuel assembly, the neutron field in the region of each specific fuel rod is subject to heterogeneous distortion, which depends on the location of the neighboring fuel rods that serve in this case as neutron absorbers generated by the IGR core. Asymmetric single-row arrangement of fuel rods in a FA is the least attractive option for testing and, as a rule, is not used for in-pile experiments due to above-mentioned and other reasons. Nevertheless, the effect can be used, for instance, to set in a particular group of fuel rods of one row with higher or lower energy release values in relation to other fuel rods.

In the case of multi-row FAs, in addition to the described above mutual influence of the fuel rods of the same row, the outer fuel rods would create "shadows" on the fuel rods in the internal rows. The neutron flux from the IGR side on the fuel rods of the inner rows would therefore be lower than that on the fuel rods of the outer rows. Accordingly, in an assembly with a uniformly distributed ${ }^{235} \mathrm{U}$, the energy release in the outer rows would be greater than that in the inner ones. 


\title{
6 Examples of achieving a given energy release profile in a fuel assembly
}

\subsection{Test object and test conditions}

A heterogeneous fuel assembly of a fast neutron reactor with a triangular lattice of fuel rods is taken as the research object. A fuel assembly contains 37 fuel rods [19] (Figure 3). By height, the fuel column (pellets) is divided into two fission zones (with ${ }^{235} \mathrm{U}$ enrichment of $17 \%$ ) and a central blanket zone (with ${ }^{235} \mathrm{U}$ content of $0.27 \%$.). The design choice is conditioned by the fact that the use of fuel assemblies which are heterogeneous in height with separation of highly-enriched fuel into two zones (upper and lower) by a layer of low-enriched fuel designed for the reproduction of fissile material, assures the negative void effect of reactivity in sodium [20]. The blanket in the center of a fuel rod, which in the event of a severe accident in a fast reactor would remain relatively cold, would affect the process of fuel melting and redistribution over the core volume. This factor can help to reduce the possibility of melting for the local masses of highly enriched fuel, and, consequently, reduce the likelihood of repeated criticality in the emergency core. In this regard, tests of the FA in the IGR are considered as a possible direction for studying the behavior of heterogeneous assemblies of future fast neutron reactors with sodium coolant in the conditions of a severe accident [21].
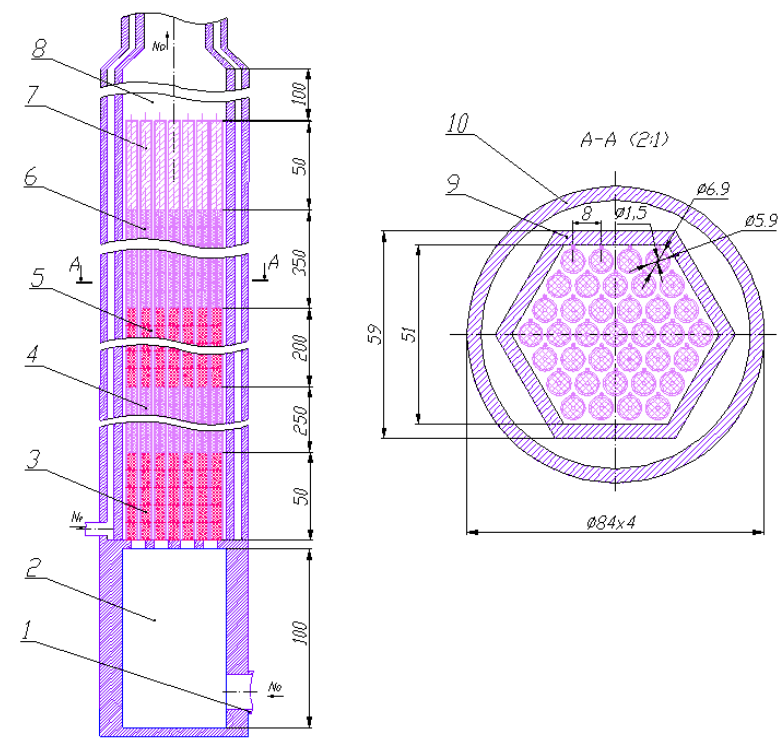

\author{
Designations: \\ 1 - sodium mouth, \\ 2 - bottom sodium plenum, \\ 3 - bottom blanket layer $\left(0.27 \%{ }^{235} \mathrm{U}\right)$, \\ 4 - bottom active layer $\left(17 \%{ }^{235} \mathrm{U}\right)$, \\ 5 - top blanket layer $\left(0.27 \%{ }^{235} \mathrm{U}\right)$, \\ 6 - top active layer $\left(17 \%{ }^{235} \mathrm{U}\right)$, \\ 7 - top plug, \\ 8 - top sodium plenum, \\ 9 - hex cover, \\ 10 -cylindrical case
}

Fig.3. Design of the irradiation device.

With in-pile tests, a number of requirements shall be met in terms of energy distribution in the experimental fuel assembly, that ensure the most complete compliance of the test conditions with the actual conditions for the occurrence and development of an emergency in the reactor under consideration:

1) provide an average energy release in the upper and lower fission zones at the level of $90.6 \mathrm{~W} / \mathrm{g}$ $\left(\mathrm{UO}_{2}\right)$ and $74 \mathrm{~W} / \mathrm{g}\left(\mathrm{UO}_{2}\right)$, respectively;

2) to exclude the possibility of power surges at the butts of the fuel rods, which can lead to local overheating of the fuel;

3) to ensure uniform radial distribution of energy release in the fuel assemblies.

\subsection{Calculation Model and Assumptions}

In the research, a detailed design model of the IGR reactor was used (Figure 4), protected by the copyright certificate [22]. The design model of the reactor is fully consistent with the real design and considers uneven distribution of uranium concentrations in the core bulk, the relocation of the control rods during startup, the dynamics of the reactor taking into account the uneven heating of individual parts of the masonry. The core, lateral, bottom, top and suspension reflectors of the IGR reactor are modeled by a block structure. 


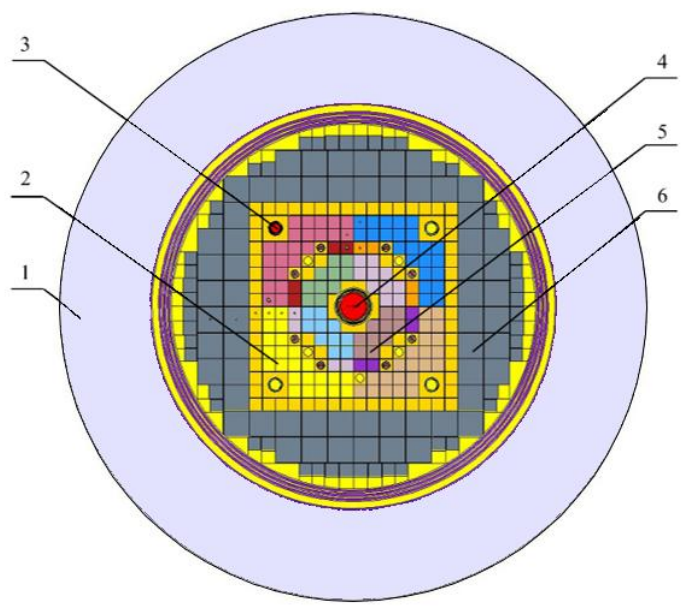

Horizontal cross-section

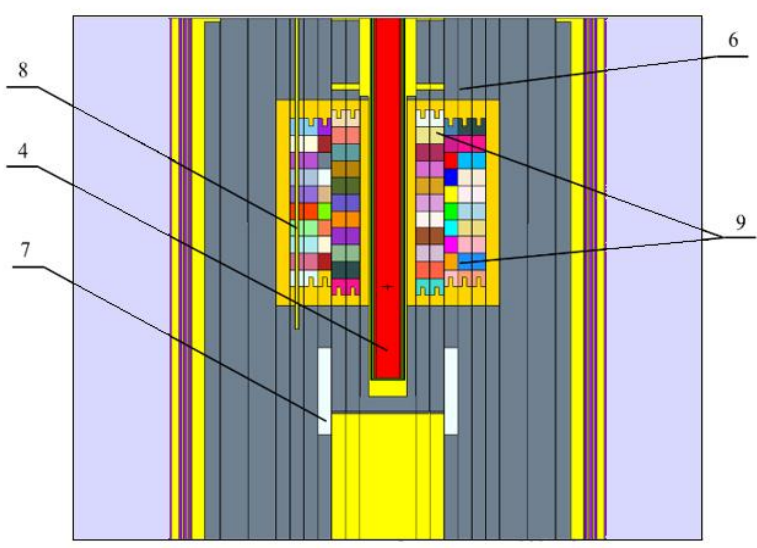

Vertical cross-section

Fig.4. Design model of the IGR reactor: 1 - water tank; 2 - fixed part of the masonry; 3 - LEC; 4 - CEC; 5 - movable masonry; 6 - reflector; 7 - boron cut-off; 8 - control rod; 9 - fuel blocks

The model is combined with irradiation device model containing heterogeneous FA, developed in compliance with all dimensional-material characteristics of the assembly and other structural elements. Figure 5 shows a horizontal cross-section of a combined design model of a device located in the CEC of the IGR reactor.

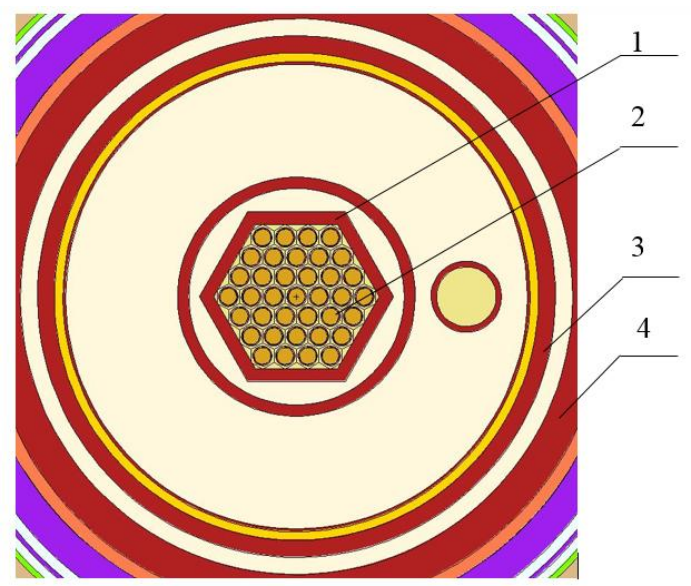

Fig.5. The model of the irradiation device as a part of the integrated calculation model: 1 - FA, 2 - fuel elements, 3 - CEC, 4 - fixed ampoule of the IGR reactor

The device design meets the main dimensional and material characteristics of the structure [1]. The fuel columns of the fuel assemblies are modeled as single rods without chamfers or grooves. All calculations were performed using the MCNP5 [23] calculation code with the ENDF/B-VII library.

\subsection{The results of the studies aimed to ensure targeted axial profile}

The targeted axial energy release profile was implemented by searching an optimal altitude location of the fuel assemblies in the CEC of the IGR reactor providing the required level and axial distribution of energy release in the fission zones. According to the calculations, the top butt of fuel rod fuel column should be $120 \mathrm{~mm}$ above the center of the IGR core. In this case, the average energy release in the upper and lower fission zones, as a whole, corresponds to the required one and comprises $90.6 \mathrm{~W} / \mathrm{g}\left(\mathrm{UO}_{2}\right)$ and $74 \mathrm{~W} / \mathrm{g}\left(\mathrm{UO}_{2}\right)$, respectively (Figure 6). 


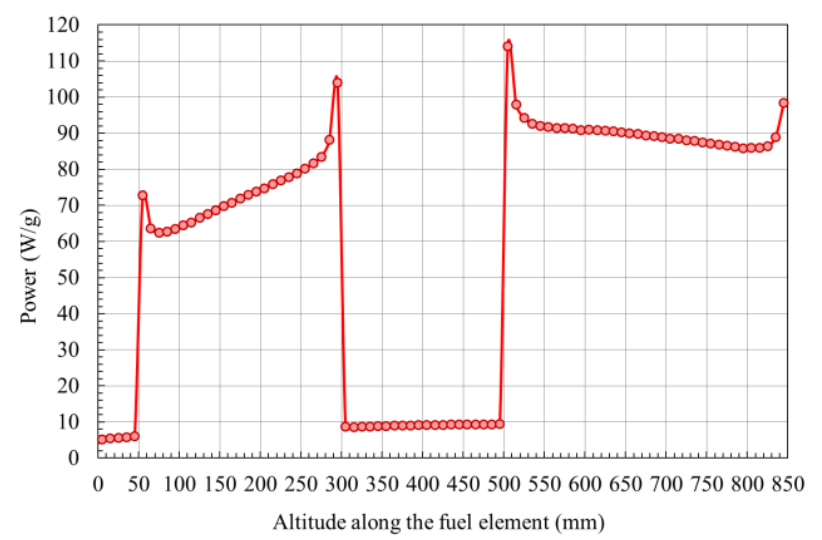

Fig.6. Axial profile of the average power along the fuel rods in the fuel assemblies

Nevertheless, significant power surges are observed at the boundaries of the fission zones due to the increased, in comparison with other regions of the fuel assemblies, neutron flux coming from the IGR. Installation of additional neutron absorbers made of steel rings at corresponding altitude of the experimental device is an option to solve the problem of smoothing the surges. The approach was used in the calculations performed to justify the experiment with a single fuel rod [24]. In the considered case, when the FA section takes up almost the entire volume of the radial section of the experimental cavity, the installation of additional rather massive structural elements is difficult due to the lack of space. To smooth out the peaks, a method is therefore proposed supposing use of pellets with lower enrichment rate or ones made of uraniumgadolinium fuel in the border regions of the fission and breeding zones.

The outcomes of the approach are shown in the graphs of Figure 7: option 1 - one pellet with ${ }^{235} \mathrm{U}$ enrichment rate of $8.25 \%$ is installed at each end of the fission zones (Figure 7a); option 2 - one pellet with $8 \%$ of $\mathrm{Gd}_{2} \mathrm{O}_{3}$ is installed at each end of the fission zones, while the fuel enrichment with ${ }^{235} \mathrm{U}$ comprises $8.25 \%$ (Figure 7b).

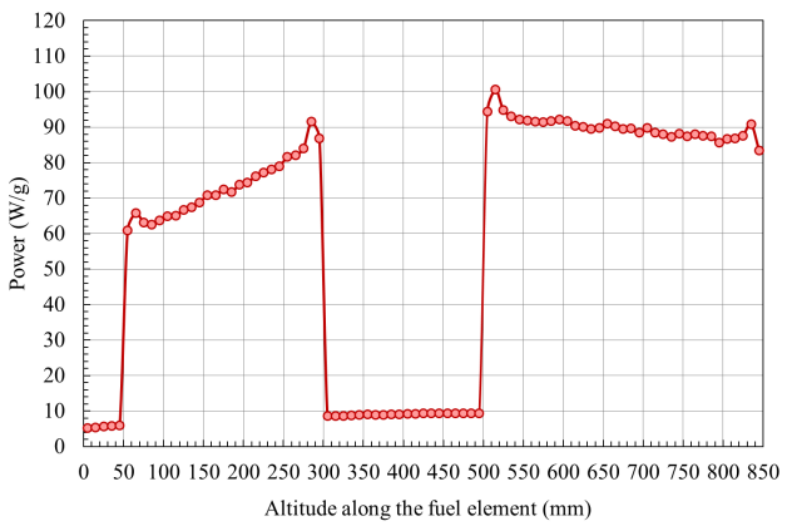

a) option 1

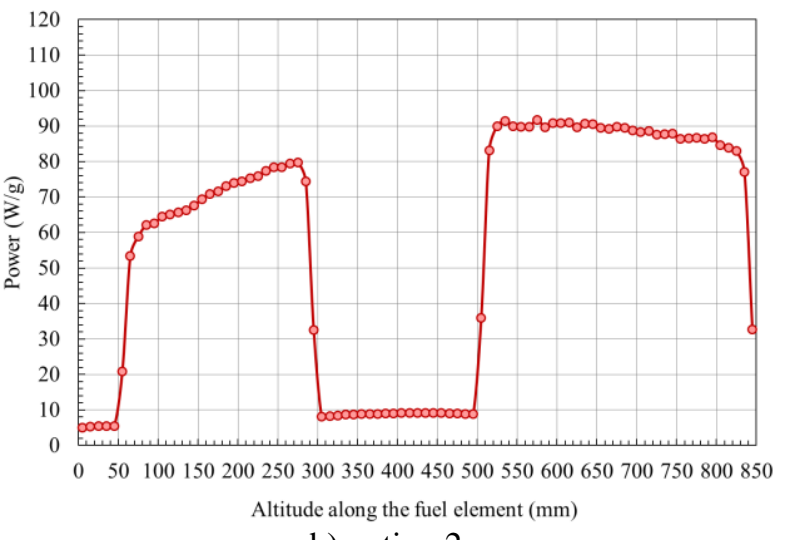

b) option 2

Fig.7. Altitude distribution of energy release in the FAs for the two considered options

As we can see, the approach is acceptable both in the case of low-enriched pellets in the border areas of the fission zones, and for the less enriched pellets made of uranium-gadolinium fuel. Thereby, application of fuel with a burnable absorber is preferable and allows to completely neutralize the local power surges.

\subsection{The results of the studies aimed at assuring the targeted radial profile}

Calculation results of FA radial profiles in the initial version demonstrated significant (for 2-2.5 times) spread of energy release along the fuel rods in radial direction (Figure 8). Profiling of the ${ }^{235} \mathrm{U}$ content in the fuel rods located on different concentric circles or rows in the fuel assemblies is the most rational solution to assure uniform radial energy release in fuel assemblies. In this case, the ${ }^{235} \mathrm{U}$ content in the fuel rods will increase with approaching to the central vertical axis of a fuel assembly [25]. 
The coefficient of the relative power non-uniformity in different fuel rod rows is used for a numerical assessment of the non-uniformity rate; the coefficient is determined as:

$$
K=\frac{W_{\text {max }}}{W_{\text {ave }}},
$$

where $W_{\max }$ - maximal energy release in the fuel rod rows, relative units; $W_{\text {ave }}$ - average energy release in the fuel rod rows, relative units.

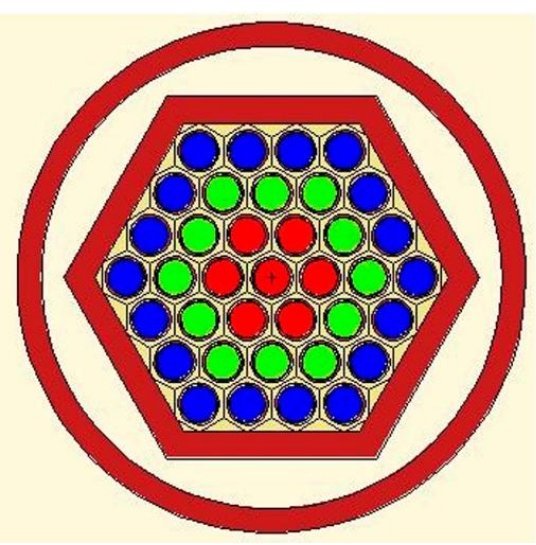

a) fuel rods in FAs

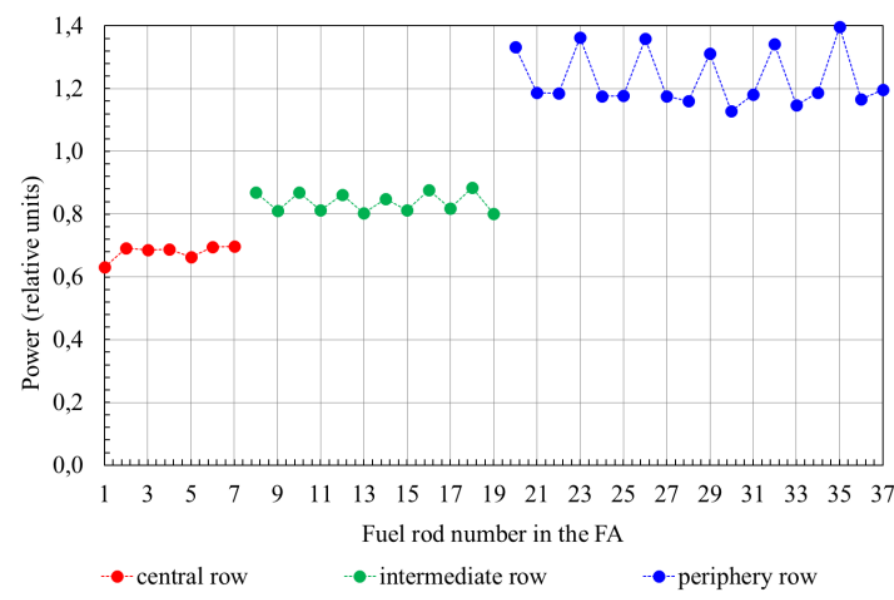

b) power distribution in FAs

Fig.8. Power distribution in the fuel rods in FAs: initial version (17\% enrichment in the fission zones)

The non-uniformity coefficient (Figure 6) comprised $\sim 1.40$. In order to reduce the uneven radial power distribution in the FAs, a complex of calculations was performed to choose enrichment profiling for the fuel rods to reduce the radial unevenness of energy release in the simulative fuel assembly (Figure 3). A satisfactory result is achieved for the option with the fuel rods enrichment in the rows $17 \%, 12.7 \%, 8.6 \%$ (Figure 9). In this case, the coefficient of unevenness is $\sim 1.10$.

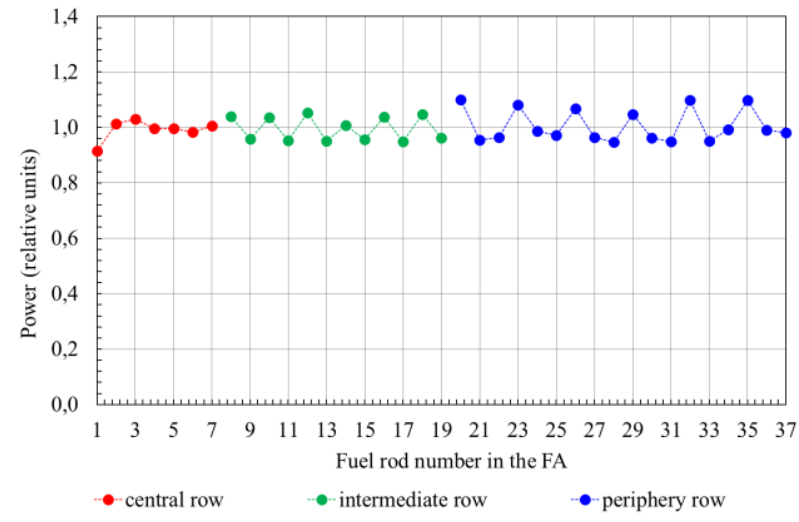

Fig.9. Power distribution in FA with enrichment in fuel rod rows are $17 \%, 12.7 \%$ and $8.6 \%$

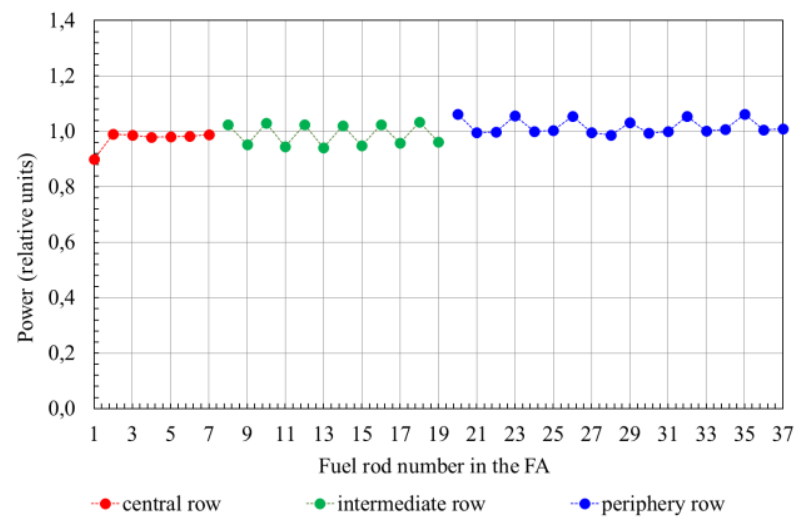

Fig.10. Power distribution in FA with enrichment in fuel rod rows are $17 \%, 12.7 \%$ and $8.94 \%$ (enrichment in peripheral row corner fuel rods is $8.25 \%$ ).

With the power distribution in the FA (Figure 6), a deviation from the average value in the peripheral row is observed. To smooth the power distribution in the peripheral row, we considered an option with reduced enrichment in the corner fuel rods to $8.25 \%$ and, simultaneous higher enrichment of remaining fuel rods in the peripheral row to $8.94 \%$. The calculation results are presented in Figure 10. With the power distribution in the fuel rods (Figure 10), the unevenness coefficient is $\sim 1.05$. 


\section{Conclusions}

Thus, the presented calculation procedure makes possible to develop and put into practice the technical solutions that assure the targeted profile of the axial and radial distribution of energy release in a simulative fuel assembly. With an example of preparation for testing in heterogeneous FA of the IGR reactor, a set of measures was demonstrated which made possible to provide uniform radial energy release and get targeted

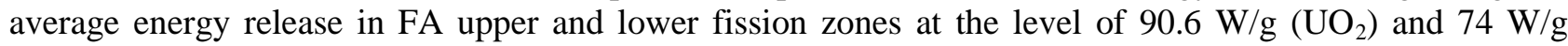
$\left(\mathrm{UO}_{2}\right)$, respectively. The measures include profiling of fuel pellets enrichment in FA rows, use of pellets with an absorber at the zone ends, and a certain altitudinal positioning of the irradiation device in the CEC IGR.

The implemented procedure is applied in preparation for tests of fuel rods and fuel assemblies in the IGR reactor and, along with other organizational and technical measures, ensures the required quality of experimental studies.

\section{Acknowledgments}

The work is carried out as part of the scientific and technical program "Development of Atomic Energy in the Republic of Kazakhstan" of the republican budget program "Development of Atomic and Energy Projects" with the support of the Ministry of Energy of the Republic of Kazakhstan.

\section{References}

1 Kurchatov I.V., Feinberg S.M., Dollezhal N.A. Pulsed graphite reactor IGR. Atomic energy. 1964, Vol. 17, No.6, pp. 463 - 474. [In Russian].

2 Royl P., Breitung W., Fischer E.A., Schumacher G., Gauntt R.O., Wright S.A. Contributions from the ACRR in-pile experiments to the understanding of key phenomena influencing unprotected loss of flow accident simulations in LMFBRs. Nuclear Engineering and Design. 1987, Vol. 100, Issue 3, pp. 387 - 408.

3 Amaya M., Udagawa Y., Narukawa T., Mihara T., Taniguchi Y. Behaviors of High-burnup LWR Fuels with Improved Materials under Design-basis Accident Conditions. Proceedings of Annual Topical Meeting on Reactor Fuel Performance (TopFuel 2018) (Internet). Prague, Czech Republic, 2018.

4 Biard B., Chevalier V., Gaillard C., Georgenthum V., et al. Reactivity Initiated Accident transient testing on irradiated fuel rods in PWR conditions: The CABRI International Program. Annals of Nuclear Energy. 2020. Vol. 141. 107253.

5 Kalcheva S., Van den Branden G., Van Dyck S., et al. Feasibility studies for simultaneous irradiation of NBSR \& MITR fuel elements in the BR2 reactor. Annals of Nuclear Energy. 2019, Vol. 127, pp. 303 - 318.

6 Holschuh Th., Woolstenhulme N., Baker B., et al. Transient Reactor Test Facility Advanced Transient Shapes. Nuclear Technology. 2019, Vol. 205(10), pp. $1346-1353$.

7 Bailly J., Tattegrain A., Saroul J. The SCARABEE facility - Its main characteristics and the experimental program. Nuclear Engineering and Design. 1980, Vol. 59, Issue 2, pp. 237 - 255.

8 Konishi K., et al. The Result of a wall failure in-pile experiment under the EAGLE project. Nuclear Engineering and Design. 2007, Vol. 237(22), pp. 2165 - 2174.

9 Kamiyama K., et al. Experimental studies on the upward fuel-discharge for elimination of severe recriticality during core-disruptive accidents in sodium-cooled fast reactors. Journal of nuclear science and technology. 2014, Vol. 51(9), pp. 1114 - 1124.

10 Serre F., Payot F., Suteau C., et al. R\&D and Experimental Programs to support the ASTRID Core Assessment in Severe Accidents Conditions. Proceedings of International Congress on Advances in Nuclear Power Plants (ICAPP), San Francisco (CA, USA). 2016, Vol. 3, pp. 2173 - 2182.

11 Vityuk G., Vurim A., Skakov M., Pakhnits A. Methods and results of determining the impurity gas amount in ceramic fuel. Annals of Nuclear Energy. 2021, Volume 150, 107843.

12 Vityuk G.A., Vurim A.D., Kotov V.M., Vityuk V.A., Zhanbolatov O.M. Calculated studies in support of inreactor tests of fast reactor fuel elements on fast neutrons. Bulletin of the National Nuclear Center of the Republic of Kazakhstan. 2017, Vol. 3, pp. 24 - 31. [In Russian].

13 Vurim A.D., Zhdanov V.S., Zverev V.V., Pivovarov O.S., Kulinich Yu.A. Results of tests of model fuel elements of the BREST-300 reactor in the IGR reactor. Bulletin of the National Nuclear Center of the Republic of Kazakhstan. 2000, Vol. 1, pp. 25 - 30.

14 Vityuk V.A., et al. Determination of the parameters for fuel assembly tests in a pulsed graphite reactor. Atomic Energy. 2016, Vol. 120, No. 5, pp. 323 - 327.

15 Vityuk V.A., Vurim A.D. Method for determining the energy parameters in pulse reactor experiments. Annals of Nuclear Energy. 2019, Vol. 127, pp. 196 - 203. 
16 Irkimbekov R.A., Vityuk V.A., et al. About the fuel tests features at the IGR research reactor. International Conference on Research Reactors: Safe Management and Effective Utilization. Book of abstracts, International Atomic Energy Agency, Vienna (Austria). November 16-20, 2015, pp.71 - 72.

17 The complex of the pulse research reactor IGR. Technological regulations: AK.65000.02.104D. Branch of the IAE RSE NNC RK, Kurchatov. 2014, Ref. No. K-52058. [In Russian].

18 Vityuk V.A., Vurim A.D., Kotov V.M., et al. Development of a model fuel assembly for an emergency study with instant blocking of the coolant flow in a fast neutron reactor. Bulletin of the National Nuclear Center of the Republic of Kazakhstan. 2018, Vol. 3 (75), pp.93 - 98. [In Russian].

19 The ASTRID technological demonstrator. 4th-Generation sodium-cooled fast reactors. December 2012 , Vol. 3, 96 pages.

20 Vurim A.D., Vityuk V.A., Gaydaychuk V.A., et al. Computational-experimental studies in support of the program of in-reactor tests of a model fuel assembly of a promising reactor. Bulletin of the National Nuclear Center of the Republic of Kazakhstan. 2015, Vol. 1, pp. 55 - 60. [In Russian].

21 Vurim A.D., Kotov V.M., Irkimbekov R.A., et al. Computer model of the IGR reactor for stationary neutronphysical calculations. The Republic of Kazakhstan certificate of authorship. December 27, 2016, No. 2738.

22 Vityuk G.A., Skakov M.K., Vityuk V.A., et al. Implementation of the energy release profile in a heterogeneous fuel element during tests in a pulsed graphite reactor. KazNITU Bulletin. 2018, Issue 6, pp. 357 - 364. [In Russian].

23 MCNP-5.1.40 Monte-Carlo N-Particle Transport Code. Los Alamos National Laboratory. Los Alamos (New Mexico). April 24, 2003.

24 Vityuk G.A., Vurim A.D., Kotov V.M., et al. Computational studies in support of intra-reactor tests of fuel rods for the fast neutron reactors. Bulletin of the National Nuclear Center of the Republic of Kazakhstan. 2017, Vol. 3 (71), pp.24-30. [In Russian].

25 Vityuk V.A. et al. Development of a model fuel assembly for investigating an emergency situation with instant blocking of the flow in a fast neutron reactor. Abstracts of VII Intern. conf. "Semipalatinsk test site. Radiation heritage and prospects for development», Kurchatov. September 21-23, 2016, pp. 128 - 129. [In Russian]. 